\title{
COUPLING ANALYSIS OF HEAT ISLAND EFFECTS, VEGETATION COVERAGE AND URBAN FLOOD IN WUHAN
}

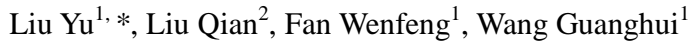 \\ ${ }^{1}$ Satellite Surveying and Mapping Application Center, NASG, Beijing 100048, China-liuy@ sasmac.cn \\ ${ }^{2}$ Heilongjiang Institute of Geomatics Engineering, Harbin 150081, China- 2924847939@qq.com
}

Commission III, WG III/1

KEY WORDS: Heat Island, Vegetation Coverage, Urban Flood, Change Detection, Wuhan

\begin{abstract}
:
In this paper, satellite image, remote sensing technique and geographic information system technique are main technical bases. Spectral and other factors comprehensive analysis and visual interpretation are main methods. We use GF-1 and Landsat8 remote sensing satellite image of Wuhan as data source, and from which we extract vegetation distribution, urban heat island relative intensity distribution map and urban flood submergence range. Based on the extracted information, through spatial analysis and regression analysis, we find correlations among heat island effect, vegetation coverage and urban flood. The results show that there is a high degree of overlap between of urban heat island and urban flood. The area of urban heat island has buildings with little vegetation cover, which may be one of the reasons for the local heavy rainstorms. Furthermore, the urban heat island has a negative correlation with vegetation coverage, and the heat island effect can be alleviated by the vegetation to a certain extent. So it is easy to understand that the new industrial zones and commercial areas which under constructions distribute in the city, these land surfaces becoming bare or have low vegetation coverage, can form new heat islands easily.
\end{abstract}

\section{INSTRUCTIONS}

With the accelerating urbanization process and the increasing city size, the urban form, function and other aspects have undergone a strong change (LUBER G, 2008a). These changes have a great impact on ecological environment especially the land surface temperature. The urban heat island effect is getting more and more attention on a global scale. It's not only causes globally change of regional climate and urban atmospheric environment but also increase the urban energy consumption and air pollution, trigger urban natural disaster, subsequently damage people's health (ZHENG B J, 2014a).

Wuhan is a fast-growing important city in the east of central China. As the city grows, impervious surface increase rapidly, lots of natural surface replaced by artificial land. With vegetation coverage going down, heat island coverage going up, this makes the effect more obvious than before. Heat island effect causes strong air convection above the city, thus causes severe convection weather, which directly lead to heavy rainfalls or storms. It is significant to study on the coupling of urban heat island, vegetation cover and urban flood for urban planning and construction, protecting ecological environment and improving the quality of life and other field applications.

\section{STUDY AREA AND DATA}

\subsection{Overview}

Wuhan is located in the Middle-lower Yangtze Plain, between east longitude $113^{\circ} 41^{\prime}-115^{\circ} 05^{\prime}$ and north latitude $29^{\circ}$ $58^{\prime}-31^{\circ} 22^{\prime}$, of subtropical moist monsoon climate, rainy and humid, with long rivers and more than 100 lakes. In the meanwhile, Wuhan is the capital city of Hubei province, and the central city of middle reaches of the Yangtze River City Group. It has a rapid development in recent years. With the accelerating process of urbanization, by the end of 2016, the urbanization rate reached $79.77 \%$. Above situations make Wuhan a heat island effect-prone area.

\subsection{Data sources and pre-process}

We choose June to July good quality images of Landsat- 8 OLI/TIRS、GF-1 as research data. Landsat-8 OLI/TIRS data is used for land surface temperature retrieval; GF-1 data is used for range extraction of vegetation coverage and rainfall flood submerged area.

In order to present real and objective land surface situation, reduce errors that caused by data, pre-processes like radiometric calibration, atmospheric correction, ortho-rectification, geometric correction, image mosaic and image clip has been done.

\section{RESEARCH METHOD}

\subsection{Land surface temperature retrieval}

Land surface heat radiation transfer equation is the basis of remote sensing retrieval of land surface temperature. TIRS on Landsat8 receives radiation flux mainly include land surface heat radiation, atmospheric ascend heat radiation, and the part that atmospheric descend heat radiation reflected to the sensor by land surface.

\footnotetext{
* Corresponding author
} 
From the radiation transfer equation, thermal infrared radiation equation that satellite sensor received can be written as below:

$$
\left.\mathrm{L}_{\lambda}=\varepsilon \mathrm{\varepsilon}\left(\mathrm{T}_{\mathrm{S}}\right)+(1-\varepsilon) \mathrm{L}_{\downarrow}\right\rceil+\mathrm{L}_{\uparrow}
$$

where $\quad \varepsilon=$ land surface emissivity

Ts $=$ radiation brightness temperature

$\mathrm{B}\left(\mathrm{T}_{\mathrm{S}}\right)=$ blackbody radiation brightness

$\tau=$ transmittance that atmospheric in thermal infrared

band

$\mathrm{L}_{\uparrow}=$ atmospheric upward radiance

$\mathrm{L}_{\downarrow}=$ atmospheric downward radiance

From the Planck function, land surface radiation brightness temperature:

$$
\mathrm{Ts}=\frac{\mathrm{K}_{2}}{\ln \left(\mathrm{K}_{1} / \mathrm{B}(\mathrm{Ts})+1\right)}
$$

For landsat8,thermal infrared band band10, K1= 774.89 $\mathrm{W} /(\mathrm{m} 2 \cdot \mu \mathrm{m} \cdot \mathrm{sr}), \quad \mathrm{K} 2=1321.08 \mathrm{~K}($ Han-Qiu X U, 2015a) Artis (Artis D A,1982a)think radiation brightness temperature is the temperature of blackbody, and most of the things in nature are not blackbody, thus emissivity should be used for correction to make it land surface temperature:

$$
\mathrm{T}=\frac{\mathrm{Ts}}{(1+(\lambda \mathrm{T} / \rho) \ln \varepsilon}
$$

where $\quad \mathrm{T}=$ land surface temperature

Ts $=$ radiation brightness temperature

$\lambda=11.5 \mu \mathrm{m}$

$\rho=0.01438 \mathrm{mk}$

$\varepsilon=$ emission

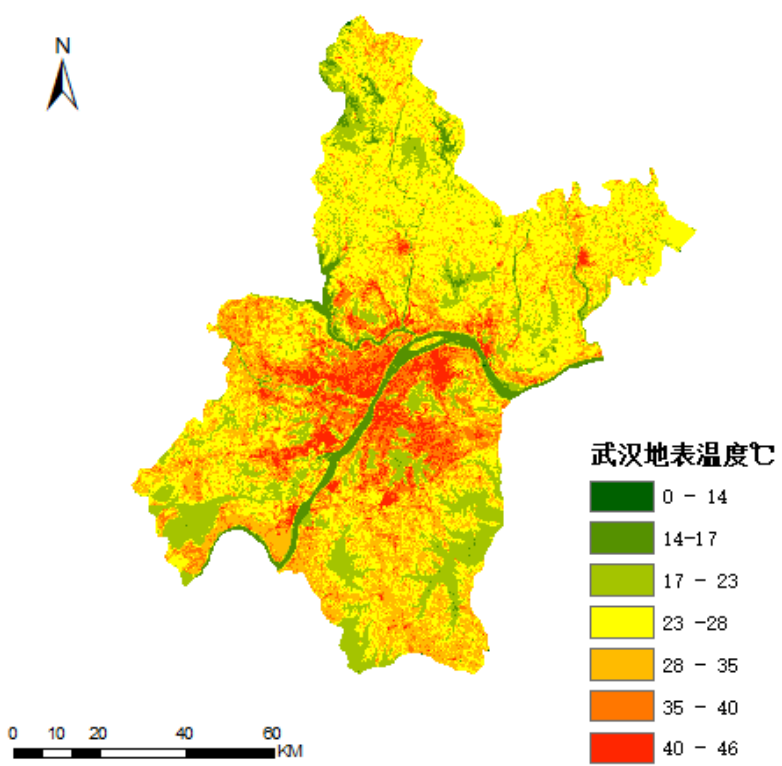

Figure 1. Surface temperature inversion of Wuhan

In order to highlight comparability and relativity, it is necessary to normalize the surface temperature. As a result, the map of heat island intensity is formed.

$$
H=\frac{t-t_{\text {min }}}{t_{\max }-t_{\min }}
$$

where $\mathrm{H}=$ Heat island intensity $\mathrm{t}=$ The surface temperature $\mathrm{t}_{\max }=$ The maximum surface temperature $\mathrm{t}_{\min }=$ The minimum surface temperature
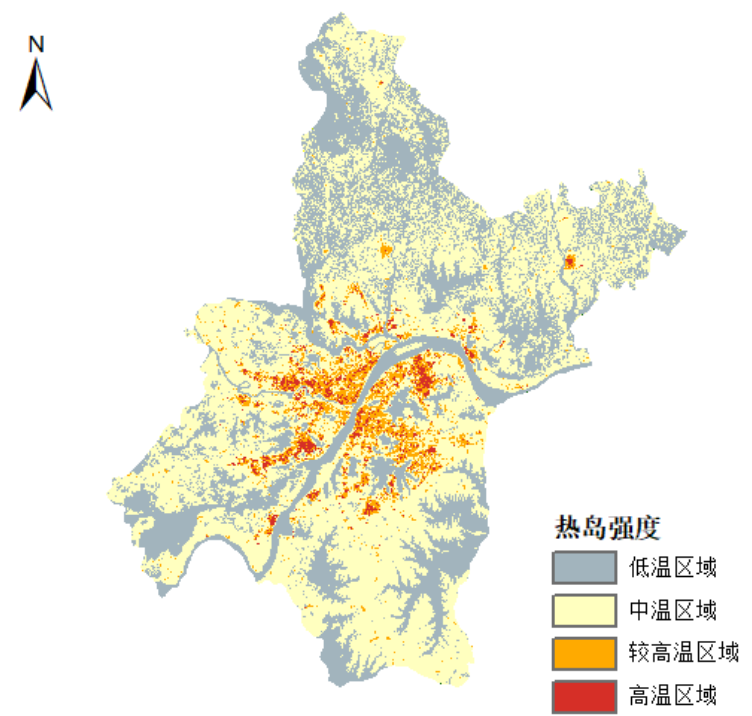

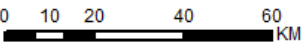

Figure 2.The map of heat island intensity

\subsection{Vegetation coverage inversion}

Vegetation coverage is mainly characterized by fractional vegetation cover (FVC) which is an important index of land surface vegetation status. FVC of Wuhan was estimated using dimidiate pixel model based on the normalized difference vegetation index (NDVI) calculated by landsat8 spectral reflectance data.

$$
\mathrm{FVC}=\frac{\text { NDVI }- \text { NDVIs }}{\text { NDVIV }- \text { NDVIs }}
$$

where $\quad \mathrm{NDVI}=$ The vegetation index bare land

NDVIs $=$ The minimum value of vegetation index in

NDVIv $=$ The maximum value of vegetation index in vegetation cover area

The dimidiate pixel model assumes that pixels are composed by vegetation ones and non-vegetation ones ( $\mathrm{Li} \mathrm{M} \mathrm{M,} \mathrm{2004a).} \mathrm{In}$ general, NDVI values of vegetation and non-vegetation take the maximum and minimum within the confidence interval to eliminate the noise caused by remote sensing images ${ }^{2}$. In this paper, the maximum value is $95 \%$ and the minimum value is $5 \%$. 


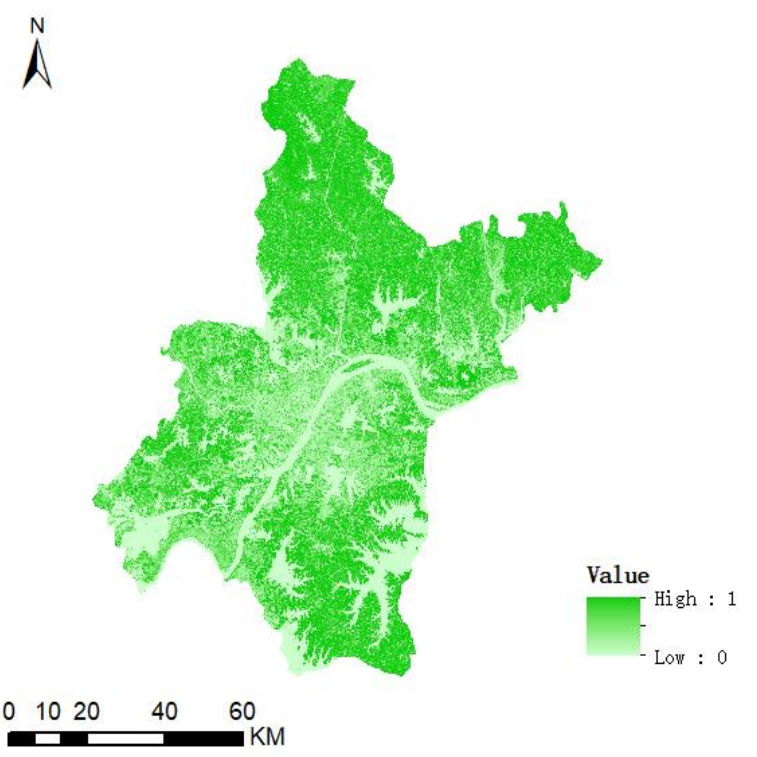

Figure 3.The fractional vegetation cover of Wuhan

\subsection{Urban rainfall flood range extraction}

In July 2016, due to the continuous heavy rainstorms, the urban flood disaster occurred in Wuhan. In order to obtain the urban flood submergence range, we monitored water at different times through GF-1 satellite images.

The most often used methods for change information extraction are direct comparison and post-classification comparison. The direct comparison method is more sensitive for extracting slight change, but this method requires relatively high quality of image radiation and affected by factors like soil moisture. So, this paper uses the post-classification comparison method to extract urban rainfall flood range.

\subsubsection{Water body information extraction}

On the basis of water body spectral characteristic, natural water has higher absorption rate than most other ground features to 0.4-2.5 $\mu \mathrm{m}$ electromagnetic wave. So in this range, water radiation would be lower than other features, the colour of water in image would be dark. In infrared band, water has strong absorption property, absorb almost all incident energy between near-infrared and mid-infrared, whereas vegetation and soil in this range absorb very small amount, and have high reflection character, appear bright colour in image. McFeeters(S K. McFeeters,1996a) proposed the concept of Normalized Differential Water Index (NDWI) for water information extraction and detection. The formula is:

$$
N D W=\frac{G-N I R}{G+N I R}
$$

where $\mathrm{G}=$ green band

NIR $=$ near-infrared band

NDWI enhance difference between water and bare soil and vegetation, emphasize water information, but due to the limitation of band range, the extracted water information often with some non-water information, especially in the aspect of urban water body extraction, building shadows frequently cause errors or omissions in extraction result (Hanqiu Xu, 2006a).
Based on the NDWI extraction result, combine the factors of colour, texture and spectral to do multi-scale segmentation, and then consider water low reflection character in NIR band, and membership function and NDWI to finish water body information extraction.

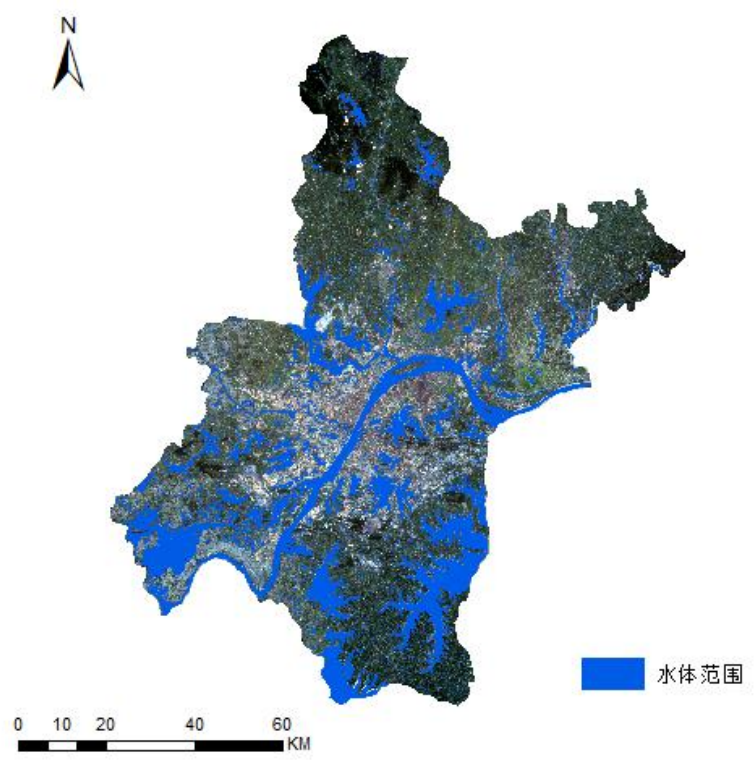

Figure 4.The scope of the water body in July 29th, 2016

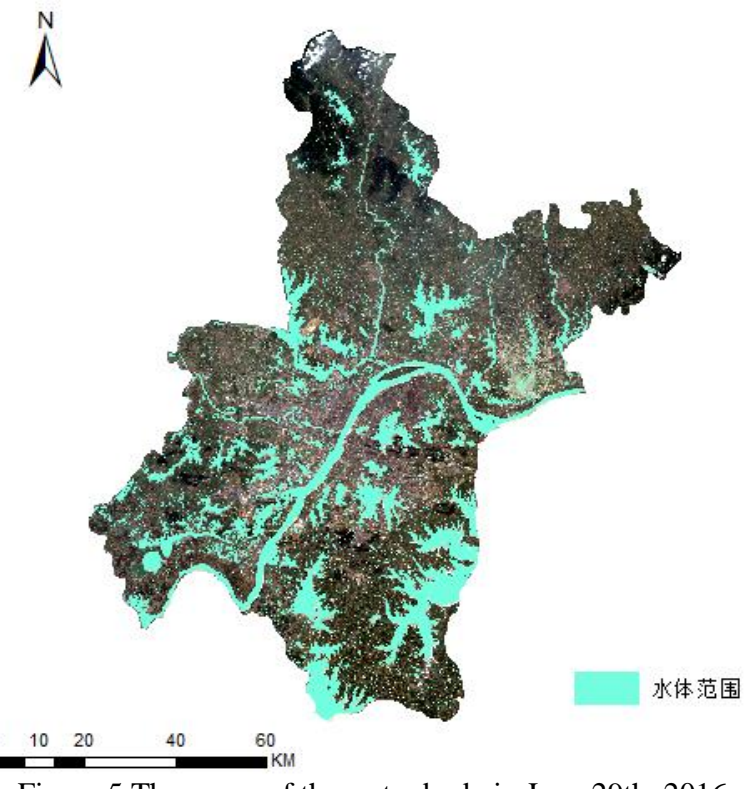

Figure 5.The scope of the water body in June 29th, 2016

\subsubsection{Change information extraction}

Use the above method to extract water body information of Wuhan from June to July in 2016, and also use the method of spatial analysis finished the water change information extraction. 


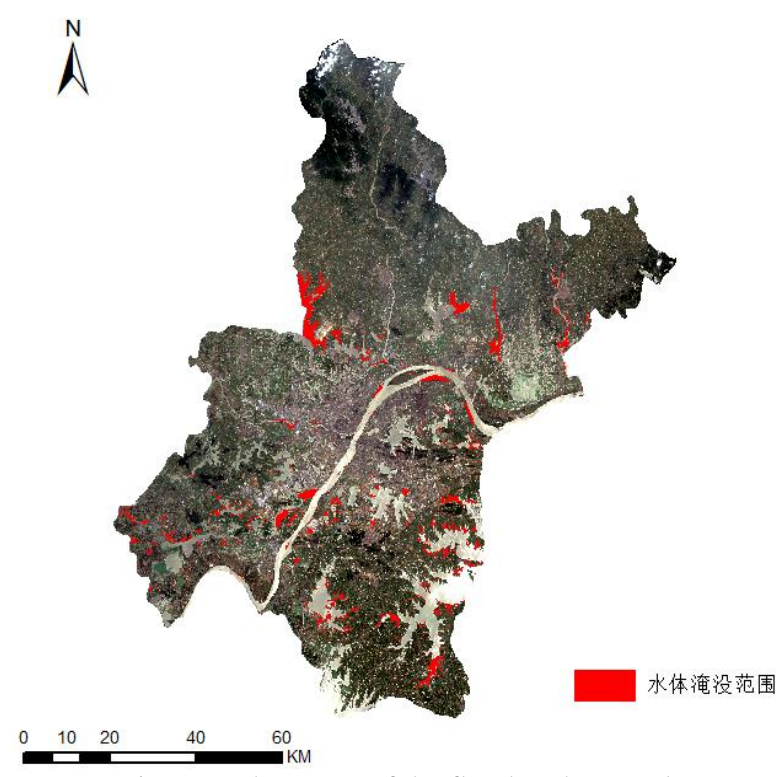

Figure 6.The scope of the floods submerged

\section{RESULT AND ANALYSIS}

\subsection{Heat island characteristics analysis}

As a whole, Urban and rural temperatures are significantly different. The main manifestation is that the urban area is the core, and the suburban urban built-up area is surrounded by scattered. The high and low temperature mutation areas are generally consistent with built-up areas. High-temperature areas are mostly concentrated in industrial areas, construction sites, steel companies, and high-density residential areas. The highest temperature area is the location of Wuhan iron and steel group. This is consistent with its industry relevance. The blast furnace ironmaking and steelmaking caused the surrounding air temperature to rise rapidly, which is higher than other areas. Compared with previous research results, it was found that the area of the heat island was enlarged, the number of heat islands increased, and the distribution was changed from local aggregation to uniform distribution. It can also be seen that some heat islands have disappeared. According to the multispectral data, we found that the disappeared heat islands are construction sites or bare grounds. As projects finish, vegetation gradually recovered and the heat island effect weakened.

\subsection{Coupling analysis of heat island and vegetation coverage}

In order to analysis of the correlation between heat island and vegetation coverage, taking Wuhan Iron and Steel Group as the center, 50 samples are randomly selected. Through the coordinate of sample points, the land surface temperature and vegetation coverage are extracted. We can use regression equation to get the relationship between the land surface temperature and vegetation coverage as shown in the following figure. Combined heat island intensity map and vegetation coverage overlay analysis results, we can found that the urban heat island has a negative correlation with vegetation coverage. The calculation shows that when the vegetation coverage is increased by $10 \%$, the temperature can be reduced by $2^{\circ} \mathrm{C}$. The heat island effect can be alleviated by the vegetation to a certain extent.

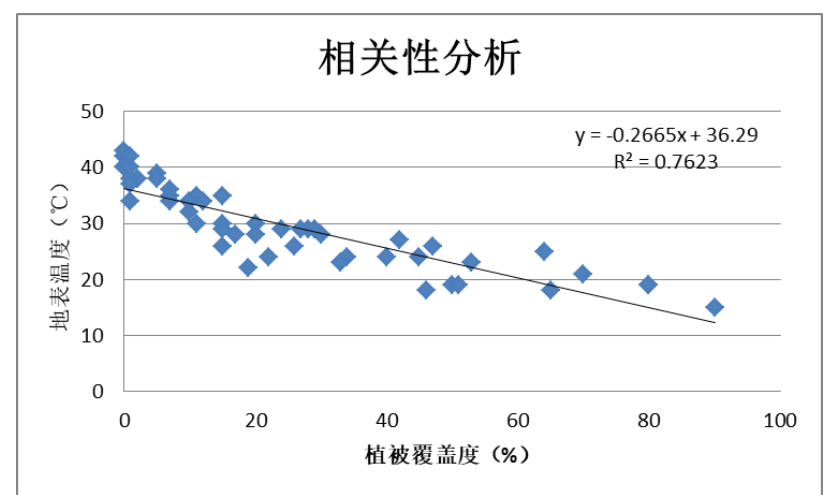

Figure 7.The analysis of heat island and vegetation coverage

\subsection{Coupling analysis of heat island and urban rainfall flood}

The flood submergence area is obtained through remote sensing image data in different periods. However, because of the time and resolution of image, the area of urban rainfall flood failed to obtain effectively. According to the distribution of water distribution maps in Wuhan issued by Wuhan Water Authority, we know that Xiongchu Street, Third Ring Road of Donghu High-tech Optics Valley Avenue, Huangjiahu University City, and other business center occurred urban rainfall flood. The overlay analysis results show that the place where the urban rainfall flood occurs has a higher temperature and in the center of or around the heat island. The main reason is that, under the action of the urban heat island, it generated the heat island circulation from the suburbs to the city which enhances air convection. The smoke in the air provides sufficient vapor condensation nuclei. As a result, urban precipitation is more than in the suburbs. The conclusion can be drawn that the heat island effect could be one of the reasons for the local heavy rainstorms.

\subsection{Coupling analysis of vegetation coverage and urban rainfall flood}

The overlay analysis results of the urban flood submergence range map and the vegetation distribution map show that there is a high probability of flooding in places where vegetation cover is poor.In the process of urbanization, large areas of farmland and vegetation are replaced by streets, factories, and residential buildings. This led to the weakening of the natural capacity of the catchment area. Rainfall can be consumed very little through interception, filling and seepage, and almost all of them enter the urban drainage system. It increased the intensity of the disaster when in the storm.

\section{CONCLUSION}

We use GF-1 and Landsat8 remote sensing satellite image of Wuhan as data source, and from which we extract vegetation distribution, urban heat island relative intensity distribution map and urban flood submergence range. Based on the extracted information, through spatial analysis and regression analysis, we find correlations among heat island effect, vegetation coverage and urban flood.

1) With the expansion of the urban area in Wuhan, the area of the heat island is gradually expanding and the number of heat islands is increasing. The distribution pattern has changed from local aggregation to random distribution. 
2) The urban heat island has a negative correlation with vegetation coverage, and the heat island effect can be alleviated by the vegetation to a certain extent.

3) The heat island effect could be one of the reasons for the local heavy rainstorms. The area of urban heat island has buildings with little vegetation cover, so the water can't be discharged from the surface. It increased the intensity of the disaster.

4) The overlay analysis results of the urban flood submergence range map and the vegetation distribution map show that there is a high probability of flooding in places where vegetation cover is poor.

5) The new industrial zones and commercial areas which under constructions distribute in the city, these land surfaces becoming bare or have low vegetation coverage. It is easy to form new heat islands. It is recommended to keep or increase vegetation coverage as much as possible while city developing.

\section{REFERENCES}

Artis D A, 1982a. Camahan W H Survey of emissive variability in thermography of urban areas. Remote Sensing of Environment, 12, pp.313-329.

Gitelson A A, Kaufman Y J, Stark R, et al, 2002. Novel algorithms for remote estimation of vegetation fraction. Remote Sensing of Environment, 80(1), pp.76-87.

Hanqiu Xu, 2006. Modification of normalised difference water index (NDWI) to enhance open water features in remotely sensed imagery. International Journal of Remote Sensing, 27(14), pp.3025-3033.

Hanqiu Xu, 2015, Retrieval of the reflectance and land surface temperature of the newly-launched Landsat 8 satellite. Chinese Journal of Geophysics, 58(3), pp.741-747.

Li M M, Wu B F, Yan C Z, 2004. Estimation of vegetation fraction in the upper basin of Miyun Reservoir by remote sensing. Resources Science, 26(4), pp.153-159.

LUBER G, MCGEEHIN M., 2008. Climate change and extreme heat events. American Journal of Preventive Medicine, 35(5), pp. 429-435.

S. K. McFEETERS, 1996. The use of the Normalized Difference Water Index (NDWI) in the delineation of open water features. International Journal of Remote Sensing, 17(7), pp.1425-1432.

Yao L I, Pan J H., 2015. Spatial pattern on urban heat environment using split window algorithm and spectral mixture analysis based on Landsat 8 images: a case of Lanzhou City. Arid Land Geography, 38(1), pp.111-119.

ZHENG B J, MYINT S W, FAN C., 2014. Spatial configuration of anthropogenic land cover impacts on urban warming. Landscape and Urban Planning, 130, pp. 104-111. 